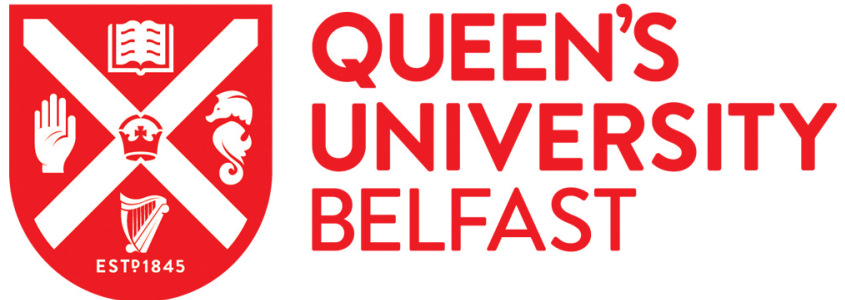

\section{Idealized Operation of Third-Harmonic-Peaking Class-EF Power Amplifier with Extended Maximum Operating Frequency}

Thian, M. (2014). Idealized Operation of Third-Harmonic-Peaking Class-EF Power Amplifier with Extended Maximum Operating Frequency. Paper presented at 21st IEEE International Conference on Electronics Circuits and Systems, Marseille, France.

\section{Document Version:}

Peer reviewed version

Queen's University Belfast - Research Portal:

Link to publication record in Queen's University Belfast Research Portal

\author{
Publisher rights \\ ( 2015 IEEE. Personal use of this material is permitted. Permission from IEEE must be obtained for all other uses, in any current or future \\ media, including \\ reprinting/republishing this material for advertising or promotional purposes, creating new collective works, for resale or redistribution to \\ servers or lists, or reuse of any copyrighted component of this work in other works
}

\section{General rights}

Copyright for the publications made accessible via the Queen's University Belfast Research Portal is retained by the author(s) and / or other copyright owners and it is a condition of accessing these publications that users recognise and abide by the legal requirements associated with these rights.

Take down policy

The Research Portal is Queen's institutional repository that provides access to Queen's research output. Every effort has been made to ensure that content in the Research Portal does not infringe any person's rights, or applicable UK laws. If you discover content in the Research Portal that you believe breaches copyright or violates any law, please contact openaccess@qub.ac.uk. 


\title{
Idealized Operation of Third-Harmonic-Peaking Class-EF Power Amplifier with Extended Maximum Operating Frequency
}

\author{
Mury Thian \\ The Queen's University of Belfast, United Kingdom
}

\begin{abstract}
A new variant of Class-EF power amplifier (PA), the so-called third-harmonic-peaking Class-EF, is presented. It inherits a soft-switching operation from the Class-E PA and a low peak switch voltage from the Class-F PA. More importantly, the new topology allows operations at higher frequencies and permits deployment of large transistors which is normally prohibited since they are always accompanied with high output capacitances. Using a simple transmission-line load network, the PA is synthesized to satisfy Class-EF impedances at fundamental frequency, third harmonic, and all even harmonics as well as to simultaneously provide an impedance matching to $50-\Omega$ load.

Index Terms - Class-E, Class-EF, Class-F, power amplifier, third-harmonic-peaking, transmission line.
\end{abstract}

\section{INTRODUCTION}

The Class-EF PA recently introduced in [1]-[4] offers a low peak switch voltage of $2 \times V_{\mathrm{DC}}$ as in the Class-F as well as softswitching operation as in the Class-E, see Fig. 1. However, the total series inductance $L+L_{0}$ is typically of large value. This large inductance is accompanied with (i) large electrical series resistance (ESR) which leads to efficiency degradation and (ii) low self-resonance frequency which restricts high-frequency implementations. Another major challenge in the Class-EF PA design is that for a given output power and DC supply voltage, the maximum operating frequency $\left(f_{\mathrm{MAX}}\right)$ is constrained by $C_{\text {OUT }}$, i.e., at high frequencies the value of $C_{\text {OUT }}$ is typically larger than the required $C$ value resulted from the Class-EF synthesis. The fact that large devices with high-powerhandling capability are always accompanied with high $C_{\text {OUT }}$ would render the Class-EF PA topology unsuitable for high power applications.

In order to address the aforementioned issues, we introduce a new variant of Class-EF PA, namely third-harmonic-peaking Class-EF PA, Fig. 2. Synthesized in the frequency domain, this PA employs a simple transmission-line load network and most importantly it allows operation at higher $f_{\mathrm{MAX}}$. The PA is designed to satisfy the Class EF impedances at fundamental frequency, third harmonic, and all even harmonics as well as to simultaneously provide an impedance matching to $50 \Omega$ load thus dispensing the need for an additional output matching circuit (i.e. unlike the PA in Fig. 1). In addition, the new PA employs novel $\lambda / 8$ open and shorted stubs which replace the traditional $\lambda / 4$ transmission line (TL). These combined two stubs offer a number of practical advantages due to their unique ability to independently control open and short circuit terminations at the collector of the transistor which would in turn improve the PA's efficiency.

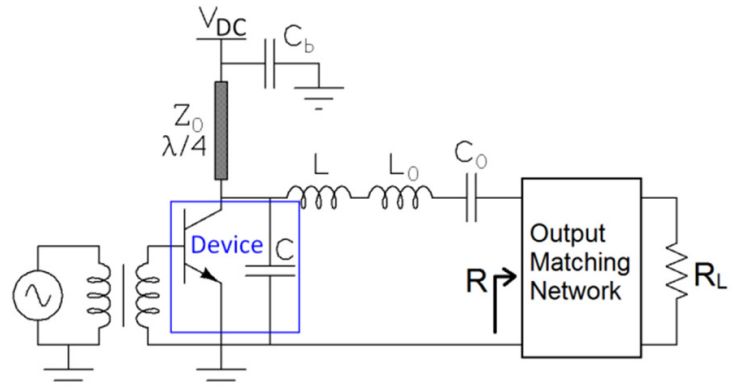

Fig. 1. Class-EF PA with lumped-element load network.

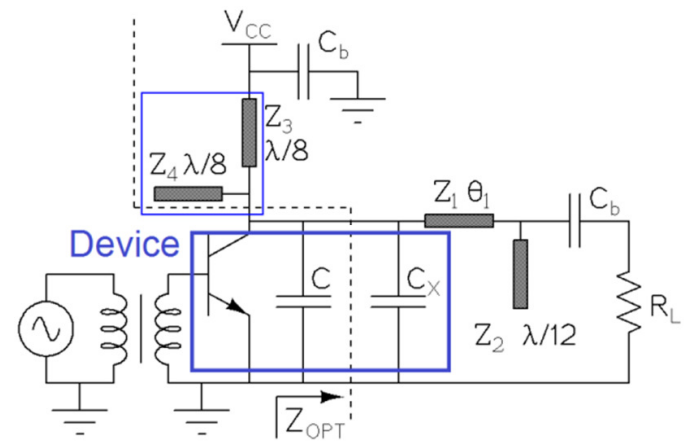

Fig. 2. Proposed third-harmonic-peaking Class-EF PA with extended maximum operating frequency.

\section{OPTIMUM IMPEDANCES OF CLASS-EF PA}

The circuit schematic of the Class-EF PA with lumpedelement load network is illustrated in Fig. 1. The shunt capacitance $C$ may entirely or partially furnish the transistor output capacitance $C_{\text {OUT }}$ and its value can be determined using (1). By substituting $C=C_{\text {OUT }}$ into (1), the expression for $f_{\text {MAX }}$, (2), can be obtained. The optimum load impedances, $Z_{\mathrm{OPT}}$, seen by the device at fundamental frequency and higher harmonics are given in (3). The load network will present $R$ in series with $L$ at $f_{0}$, a short circuit at all even harmonics, and an open circuit at all odd harmonics. For prescribed output power $\left(P_{\mathrm{O}}\right)$, DC supply voltage $\left(V_{\mathrm{DC}}\right)$, and operating frequency $\left(f_{0}\right)$, the optimum load resistance $R$ and series inductance $L$ can be calculated using (4) and (5).

The short-circuit requirement at even harmonics will be enforced by a $\lambda / 4$ transmission line that is connected at the collector of the transistor. The relationship between the parameter $\tau_{\mathrm{D}}$ in (1)-(5) and duty ratio $D$ is given by $D=0.5-$ $\tau_{\mathrm{D}} /(2 \pi)$. For example, $\tau_{\mathrm{D}}=\pi / 2 \mathrm{rad}$ or $90^{\circ}$ corresponds to $D=0.25$ meaning that the transistor will be switched on only for a $25 \%$ period of the full cycle. 
$C=\frac{\pi}{2}\left(\frac{\sin \tau_{D}}{1+\cos \tau_{D}}\right)^{2} \frac{P_{O}}{\omega_{0} V_{D C}^{2}}$

$f_{\text {MAX }}=\frac{1}{4}\left(\frac{\sin \tau_{D}}{1+\cos \tau_{D}}\right)^{2} \frac{P_{O}}{C_{O U T} V_{D C}^{2}}$

$Z_{\text {OPT }}=\left\{\begin{array}{cl}R+j \omega_{0} L & \text { at } f_{0} \\ 0 & \text { at } 2 n f_{0}, n=1,2,3, \ldots \\ \infty & \text { at }(2 n+1) f_{0}, n=1,2,3, \ldots\end{array}\right.$

$R=\frac{2\left(1+\cos \tau_{D}\right)^{2}}{\pi^{2}} \frac{V_{D C}^{2}}{P_{O}}$

$L=\frac{\tau_{D}-0.5 \sin \left(2 \tau_{D}\right)}{\sin ^{2} \tau_{D}} \frac{R}{\omega_{0}}$

\section{ANALYSIS OF THIRD-HARMONIC-PEAKING CLASS-EF PA}

A new Class-EF PA circuit topology with transmission-line load network is depicted in Fig. 2. In practice, it is impossible to realize a transmission-line load network that would satisfy Class-EF impedance requirements at fundamental frequency as well as all even and odd harmonics, (3), since that would require an infinite number of transmission lines. However, as will be shown shortly, a good approximation to the idealized Class-EF operation can be achieved by satisfying the required impedances at $f_{0}$, all even harmonics, and only the first few odd harmonics. Here, a third-harmonic-peaking Class-EF PA is proposed with the open-circuit requirement satisfied at $3 f_{0}$ alone. The circuit is also analyzed to simultaneously provide an impedance matching to $50-\Omega$ load.

An extra capacitance $C_{\mathrm{X}}$ is added to the circuit and, as a result, the device output capacitance $C_{\mathrm{OUT}}$ now increases to $C+C_{\mathrm{X}}$. This translates into higher $f_{\mathrm{MAX}}$ expressed in (6) where $C_{\mathrm{X}}$ is defined as $k C(k>0)$.

$f_{\text {MAX }}=\frac{1}{4}\left(\frac{\sin \tau_{D}}{1+\cos \tau_{D}}\right)^{2}(1+k) \frac{P_{o}}{C_{\text {OUT }} V_{D C}^{2}}$

The electrical length of the open-circuit stub $\mathrm{TL}_{2}$ in Fig. 2 is $90^{\circ}$ at $3 f_{0}$ (i.e. $30^{\circ}$ at $f_{0}$ ) and therefore it provides a shortcircuit termination to the series line $\mathrm{TL}_{1}$. This shorted series line behaves like an inductance $\left(L_{1}\right)$. This inductance must be resonated with $C_{\mathrm{X}}$ in order to provide the required Class-EF open circuit at $3 f_{0}$, from which we can derive (7).

$3 \omega_{0} C_{X} \tan \left(3 \theta_{1}\right)=Y_{1}$

At fundamental frequency, the $50 \Omega$ load resistance $\left(R_{\mathrm{L}}\right)$ is transformed by $\mathrm{TL}_{1}$ and $\mathrm{TL}_{2}$ to an admittance of $1 / Z_{\mathrm{OPT}}$ $j \omega_{0} C_{\mathrm{X}}$ where $Z_{\mathrm{OPT}}$ is given in (3). This results in:

$$
\begin{aligned}
& G_{O P T}=\frac{G_{L} Y_{1}^{2} \sec ^{2} \theta_{1}}{\left(Y_{1}-B_{L} \tan \theta_{1}\right)^{2}+G_{L}^{2} \tan ^{2} \theta_{1}} \\
& \frac{B_{O P T}-\omega_{0} C_{X}}{Y_{1}}=\frac{\left(Y_{1} \tan \theta_{1}+B_{L}\right)\left(Y_{1}-B_{L} \tan \theta_{1}\right)-G_{L}^{2} \tan \theta_{1}}{\left(Y_{1}-B_{L} \tan \theta_{1}\right)^{2}+G_{L}^{2} \tan ^{2} \theta_{1}} \\
& G_{O P T}=\frac{R}{R^{2}+\left(\omega_{0} L\right)^{2}} \\
& B_{O P T}=\frac{-\omega_{0} L}{R^{2}+\left(\omega_{0} L\right)^{2}}
\end{aligned}
$$

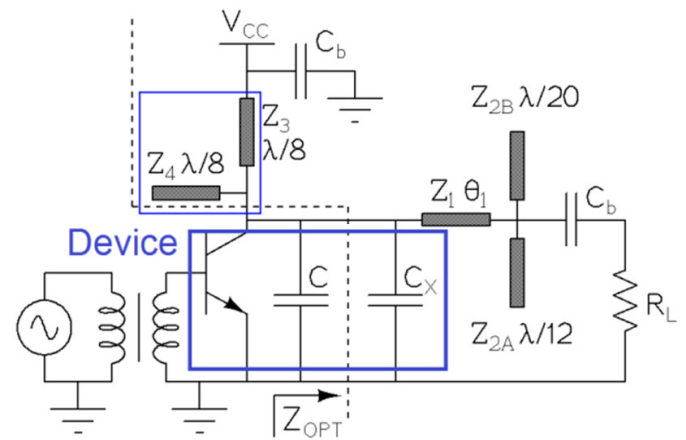

Fig. 3. Modified third-harmonic-peaking Class-EF PA.

$G_{L}=1 / R_{L}=1 / 50$

$B_{L}=Y_{2} \tan 30^{\circ}=Y_{2} / \sqrt{3}$

By solving (7)-(9) simultaneously, the values of $Z_{1}\left(=1 / Y_{1}\right)$, $\theta_{1}$, and $Z_{2}\left(=1 / Y_{2}\right)$ can be obtained. Further, to facilitate for fifth-harmonic suppression, the open-circuit stub $\left(Z_{2}, 30^{\circ}\right)$ in Fig. 2 is modified into two open-circuit stubs with electrical lengths of $30^{\circ}$ and $18^{\circ}$, Fig. 3. The new characteristic admittances $Y_{2 \mathrm{~A}}$ and $Y_{2 \mathrm{~B}}$ can be calculated as follows

$Y_{2 \mathrm{~A}}=Y_{2 \mathrm{~B}}=\frac{Y_{2} \tan 30^{\circ}}{\tan 30^{\circ}+\tan 18^{\circ}} \approx 0.64 Y_{2}$

where $Y_{2 \mathrm{~A}}=1 / Z_{2 \mathrm{~A}}$ and $Y_{2 \mathrm{~B}}=1 / Z_{2 \mathrm{~B}}$.

\section{ANALYSIS OF $\lambda / 8$ OPEN AND SHORTED STUBS}

Novel $\lambda / 8$ open and shorted stubs depicted in Figs. 2-3 are proposed to replace the traditional $\lambda / 4$ line, Fig. 1 . The $\lambda / 8$ open stub will short circuit the collector of the transistor at $(4 m-2)^{\text {th }}$ harmonics whereas the $\lambda / 8$ shorted stub will short circuit the collector of the transistor at $4 m^{\text {th }}$ harmonics where $m=1,2,3$, etc. Together they will facilitate a short-circuit termination at all even harmonics. At fundamental frequency, the $\lambda / 8$ shorted stub behaves like an inductance (15) while the $\lambda / 8$ open stub behaves like a capacitance (16). This parallel $L_{3}-C_{4}$ circuit should resonate at $f_{0}(17)$.

$$
\begin{aligned}
& j \omega_{0} L_{3}=j Z_{3} \tan 45^{\circ}=j Z_{3} \\
& j \omega_{0} C_{4}=j Y_{4} \tan 45^{\circ}=j Y_{4} \\
& \omega_{0}^{2} L_{3} C_{4}=1
\end{aligned}
$$

Substitutions of (15) and (16) into (17) would result in $Z_{3}=Z_{4}$. By setting $Z_{3}$ equal to $Z_{4}$, it can be proven that this stub arrangement will provide an open circuit not only at $f_{0}$ but also at all odd harmonics. The characteristics of the $\lambda / 8$ open and shorted stubs at $f_{0}$, even and odd harmonics are compared with the $\lambda / 4$ line in Fig. 4. It can be observed that the former offers wider rejection band but narrower pass band than the latter.

The bypass capacitor $C_{\mathrm{b}}$ in Fig. 1 should in theory provide a short circuit at the fundamental frequency as well as at all even and odd harmonics. However, in practice, one capacitor can only be used to provide low impedance $(\sim 1 \Omega)$ at a single frequency. For example, in order to provide a short circuit at $f_{0}, 2 f_{0}, \ldots, 6 f_{0}$, six capacitors of different values connected in parallel are needed. In contrast, the PAs in Figs. 2-3 only need 4 capacitors since the short-circuit terminations at the collector at $2 f_{0}$ and $6 f_{0}$ are enforced by the $\lambda / 8$ open stub and therefore 


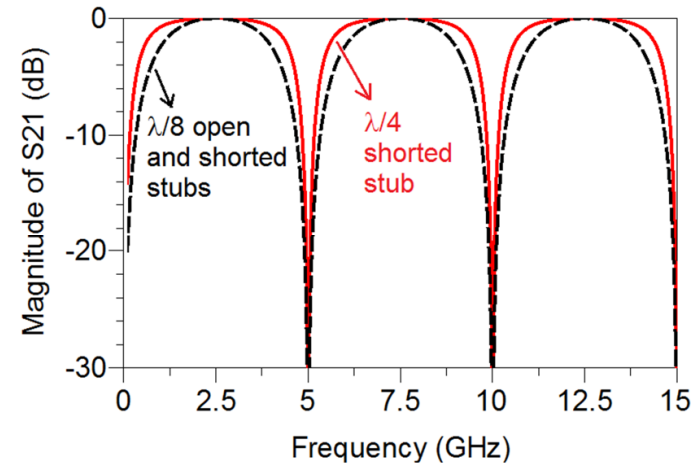

Fig. 4. Characteristics of $\lambda / 8$ open $\&$ shorted stubs vs $\lambda / 4$ TL.

no capacitors are required. Another practical advantage is that the $\lambda / 8$ open stub will present lower impedance (close to $0 \Omega$ ) at the collector resulting in better $2^{\text {nd }}$ and $6^{\text {th }}$ harmonics suppressions than the case when a $\lambda / 4 \mathrm{TL}$ and $C_{\mathrm{b}}$ are used, i.e., due to the ESR of $C_{\mathrm{b}}$.

\section{DESIGN PROCEDURES AND SiMUlation RESUltS}

To validate the theoretical synthesis treated in Sections IIIIV, a design example of the third-harmonic-peaking Class-EF PAs with extended $f_{\text {MAX }}$ (Figs. 2-3) is given here. The design specifications are $f_{0}=2.5 \mathrm{GHz}, V_{\mathrm{DC}}=5 \mathrm{~V}, P_{\mathrm{O}}=0.5 \mathrm{~W} . \tau_{\mathrm{D}}=$ $48.5^{\circ}$ is chosen so as the $P_{\text {MAX }}$ is $35 \%$ higher than the ClassE's [3].

Step 1: Calculate the values of $C, R$ and $L$ using (1), (4) and (5) respectively.

Step 2: Calculate $C_{\mathrm{X}}=C_{\mathrm{OUT}}-C$. $C_{\mathrm{OUT}}$ can be obtained from the device manufacturer catalogues, device model simulations, or from device sample measurements.

Step 3: Calculate the transmission-line parameter values $Z_{1}$, $\theta_{1}$, and $Z_{2}$ using (7)-(13).

Step 4: Calculate the characteristic impedances $Z_{2 \mathrm{~A}}$ and $Z_{2 \mathrm{~B}}$ using (14).

Step 5: Following the derivation and discussion in Section IV, $Z_{3}$ and $Z_{4}$ should be set equal and their values should be selected as high as the practical implementation would allow.

The optimal circuit component values for the case when $f_{\mathrm{MAX}}$ is increased by $25 \%(k=0.25)$ are given in Table I. The steady-state waveforms and the output power spectra obtained using the harmonic balance simulations in Agilent Advanced Design Systems (ADS) are illustrated in Figs. 5-6. Aligned with the theory, the peak switch voltage is $2 \times V_{\mathrm{DC}}=10 \mathrm{~V}$ and clean output power spectra is achieved up to as high as sixth harmonic, i.e., $2^{\text {nd }}$ and $6^{\text {th }}$ harmonics are suppressed by the $\lambda / 8$ open stub, $4^{\text {th }}$ harmonic is suppressed by the $\lambda / 8$ shorted stub, $3^{\text {rd }}$ and $5^{\text {th }}$ harmonics are suppressed by $\mathrm{TL}_{2 \mathrm{~A}}$ and $\mathrm{TL}_{2 \mathrm{~B}}$. As a result, an undistorted sine wave was obtained at the output.

\section{CONCLUSIONS}

The analysis and design of the third-harmonic-peaking Class-EF PA including the method to increase the PA's maximum operating frequency have been presented. The validity of the analytical derivation has been confirmed through harmonic-balance simulations.
TABLE I Optimal Circuit Component Values

\begin{tabular}{|cc|cc|}
\hline$k$ & 0.25 & $Z_{3}=Z_{4}$ & $80 \Omega$ \\
$C$ & $0.4 \mathrm{pF}$ & $\theta_{1}$ & $19.2^{\circ}$ \\
$Z_{1}$ & $132.4 \Omega$ & $\theta_{2}=\theta_{2 \mathrm{~A}}$ & $30^{\circ}$ \\
$Z_{2}$ & $31.2 \Omega$ & $\theta_{2 \mathrm{~B}}$ & $18^{\circ}$ \\
$Z_{2 \mathrm{~A}}=Z_{2 \mathrm{~B}}$ & $48.8 \Omega$ & $\theta_{3}=\theta_{4}$ & $45^{\circ}$ \\
\hline
\end{tabular}
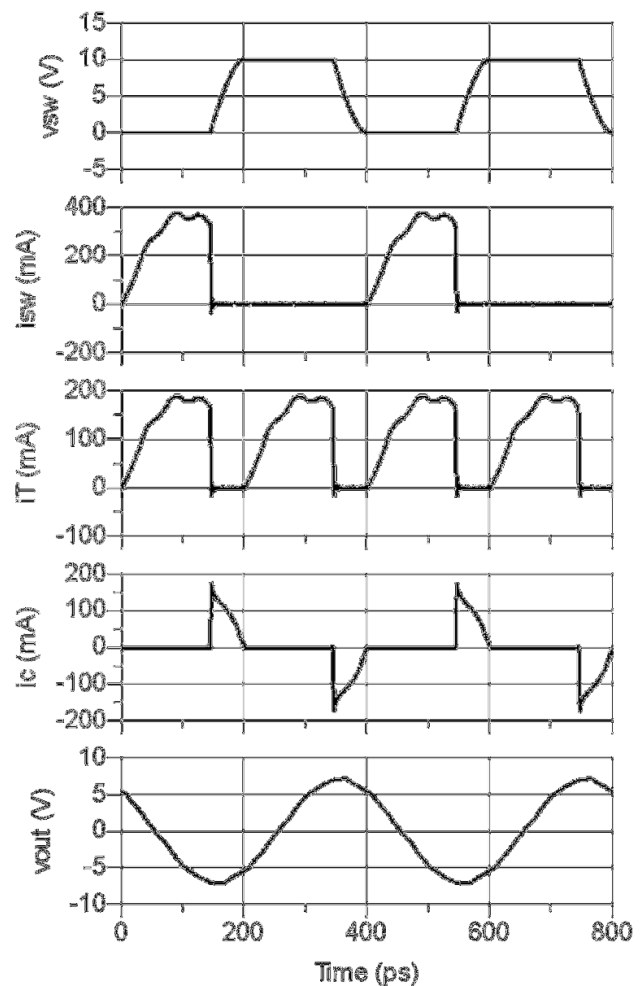

Fig. 5. Idealized steady-state voltage and current waveforms.

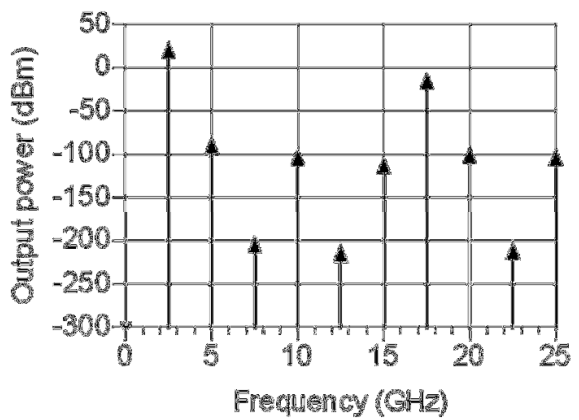

Fig. 6. Output power spectra up to $10 f_{0}$.

\section{REFERENCES}

[1] J. W. Phinney, D. J. Perreault, and J. H. Lang, "Radio-frequency inverters with transmission-line input networks," IEEE Trans. Power Electron., vol. 22, no. 7, pp. 1154-1161, Jul. 2007.

[2] A. Grebennikov, "High-efficiency Class-FE tuned power amplifiers," IEEE Trans. Circuits Syst. I, Reg. Papers, vol. 55, no. 10, pp. 3284-3292, Nov. 2008.

[3] M. Thian and V.F. Fusco, "Analysis and design of Class- $\mathrm{E}_{3} \mathrm{~F}$ and transmission-line Class- $\mathrm{E}_{3} \mathrm{~F}_{2}$ power amplifiers," IEEE Trans. Circuits Syst. I, vol. 58, no. 5, pp. 902-912, May 2011.

[4] Z. Kaczmarczyk, "High-efficiency Class E, EF2, and E/F3 inverters," IEEE Trans. Ind. Electron., vol. 53, no. 5, pp. 15841593, Oct. 2006. 